\title{
Immunochemical Characterization of the Specific Sequence of URG7 Protein
}

\author{
Ostuni $A^{1^{*}}$, Cuviello $F^{1}$, Salvia AM $^{1}$, D'Auria $F^{2}$, Statuto $T^{2}$, Di Nardo $E^{3}$, Miglionico $\mathbf{R}^{1}$, Carretta $\mathrm{V}^{4}$, Musto $\mathrm{P}^{2}$ and Bisaccia $\mathrm{F}^{1}$ \\ ${ }^{1}$ Department of Sciences, University of Basilicata, 85100 Potenza, Italy \\ 2Laboratory of Clinical Research and Advanced Diagnostics, IRCCS-CROB, 85028 Rionero in Vulture, Italy \\ ${ }^{3}$ Department of Mathematics, Computer Science and Economics, University of Basilicata, 85100 Potenza, Italy \\ ${ }^{4}$ Hospital of Venosa, Unit of Medicine, 85029 Venosa, Italy
}

*Corresponding author: Ostuni A, Department of Sciences, University of Basilicata, 85100 Potenza, Italy, Tel: +39-0971205453; Fax: +39-0971205678; E-mail: angela.ostuni@unibas.it

Received date: August 11, 2016; Accepted date: September 02, 2016; Published date: September 10, 2016

Copyright: (C) 2016 Ostuni A, et al. This is an open-access article distributed under the terms of the Creative Commons Attribution License, which permits unrestricted use, distribution and reproduction in any medium, provided the original author and source are credited.

\begin{abstract}
URG7 is an anti-apoptotic protein which consists of 99 amino acid residues up regulated by antigen $\mathrm{x}$ during the HBV infection. The first 74 amino acids are identical to those of the multidrug resistance protein 6 (MRP6), while the amino acid residues from 75 to 99 are specific for URG7 protein. Immuno-informatics tools and secondary structure analysis were carried out to identify the antigenic properties of this URG7 sequence. The 75-99 peptide was synthesized by the solid-phase method, structurally characterized by CD spectroscopy and conjugated to a protein carrier. New Zealand white rabbits were immunized and sera were tested for anti-peptide specific antibodies by ELISA and western blot analysis. Finally ELISA test with human sera was performed.

Rabbits immunized with the 75-99 peptide produce antibodies that recognize both the 75-99 peptide and the URG7 recombinant polypeptide. Moreover, both antigens allowed for the detection of the anti-URG7 antibodies in sera of healthy and HBV infected subjects although with a different discriminant threshold. Our data suggested that peptide ELISA assay against the specific sequence of the URG7 protein allows with good sensitivity and specificity for the detection of anti-URG7 antibodies in sera from HBV infected patients.
\end{abstract}

Keywords: ELISA; Immunogenic peptide; Hepatitis B virus; Preneoplastic marker; URG7

\section{Introduction}

In the hepatocytes infected by the hepatitis $\mathrm{B}$ virus (HBV), the hepatitis $\mathrm{B}$ virus $\mathrm{X}(\mathrm{HBx})$ protein has a crucial role in the pathogenesis of chronic infection and the development of hepatocellular carcinoma (HCC). HBx trans-activates a large number of signaling pathways and cellular genes that are involved in oncogenesis, proliferation, inflammation and immune responses [1-3], regulates protein stability via interaction with proteasome subunits [4] and more recently was reported to be able to regulate microRNA expression [5]. One of the cellular genes whose expression is up-regulated by $\mathrm{HBx}$ is the UpRegulated Gene clone 7 (URG7). This gene encodes a protein of 99 amino acids which is highly homologous with the amino terminal of the multidrug resistance protein 6 (MRP6) $[6,7]$. This protein belongs to the ABC family of transport proteins (ATP Binding Cassette) and is encoded by the ABCC6 gene, whose mutations are associated with the genetic disease Pseudoxanthoma elasticum $[8,9]$.

Studies carried out on HepG2 cells transfected with the URG7 gene indicated that the encoded protein stimulated the growth of cells in serum free medium and partially protected cells from anti-Fas mediated killing by means of an anti-apoptotic activity mediated by caspases 3 and 8 [10]. Moreover, URG7 activates the transduction pathway of the PI3K/AKT signal and $\beta$-catenin too, suggesting that it contributes to sustaining chronic virus infection which later plays a role in the development of HCC [11]. URG7 expressed in HepG2 cells localizes in the endoplasmic reticulum with an $\mathrm{N}_{\text {lumen }}-\mathrm{C}_{\text {cytosol }}$ orientation [12,13]. Actually, little information is available on the structural properties of the URG7 protein: circular dichroism and fluorescence spectroscopy studies showed that the His-URG7 polypeptide expressed in Escherichia coli assumes secondary structures in non-polar solvents and in micellar solutions of SDS, reasonable with its localization within the endoplasmic reticulum [14].

Some of the HBx associated up-regulated genes (URGs) trigger corresponding antibodies in the sera of patients at the early stage tumorigenesis, suggesting that the anti-URGs antibodies may have diagnostic/prognostic utility among patients at high risk for the development of cirrhosis and/or HCC. In particular, in the serum of infected patients who will develop HCC, it was found that various combinations of different anti-URG antibodies, either alone or in combination with existing markers, may increase the chances of identifying patients at high risk for cirrhosis and/or HCC or with early cirrhosis and/or HCC $[15,16]$. However, it is noteworthy that the peptides used in these previous ELISA tests spanned the amino acid (aa) sequences $12-25$ and $56-70$ of the URG7 protein, actually corresponding to the amino acid sequence of the MRP6 [15].

In the present work, we report the antigenic and structural features of the synthetic peptide corresponding to the unique sequence aa75-99 belonging to the URG7 protein to develop an ELISA test for specifically evaluating the presence of anti-URG7 antibodies in the serum of patients affected by hepatitis virus infection. 


\section{Materials and Methods}

\section{Peptide synthesis and structural analysis}

The portion of the peptide spanning aa75-99 (75AAIPGSLEPGNVRGRQGTGWNLVKS99) and corresponding to the last 25 amino acids of the URG7 protein was synthesized on a Pioneer PerSeptive Biosystem synthesizer by the solid-phase method using Fmoc chemistry. Coupling reagents (0.5 M PyBop/DMF and 1.0 M DIPEA/DMF) were used with a four-fold excess of amino acid. A TFA $/ \mathrm{H}_{2} \mathrm{O} /$ thioanisole/phenol/isopropyl silane $(88 \%, 3 \%, 3 \%, 4 \%$, and $2 \%)$ mixture was used for the final deprotection and cleavage of the peptides. Crude peptide was precipitated in cold diethyl ether, then lyophilized and finally purified using reverse-phase HPLC on a Phenomenex C18 column $(2.5 \times 300 \mathrm{~mm}, 5 \mu \mathrm{m}$ particles $)$ using a gradient of acetonitrile/water in $0.1 \%$ TFA [17]. The molecular mass of the peptide was confirmed by mass spectroscopy. Protein concentration was determined by measuring the optical absorbance at $280 \mathrm{~nm}$ using $5500 \mathrm{M}^{-1} \mathrm{~cm}^{-1}$ as the extinction coefficient calculated from the amino acid composition.

CD spectra were recorded on a Jasco J-815 CD Spectrometer with a Xenon 250W lamp and peptide solution $(50 \mu \mathrm{M}$ in $10 \mathrm{mM}$ phosphate buffer $\mathrm{pH}$ 6). The acquisition was carried out in a cylindrical quartz thermostated cell with an optical path of $1 \mathrm{~mm}$, in the spectral range of 190-250 nm, with a scanning speed of $100 \mathrm{~nm} / \mathrm{min}$, a bandwidth of 1 $\mathrm{nm}$, a time-constant of $0.5 \mathrm{~s}$, a sensitivity of $20 \mathrm{mdeg}$ and a total number of 16 accumulations for each spectrum. The baseline spectrum of the solvent was subtracted and peptide spectrum was smoothed using the Fourier transform. Data were expressed in terms of the molar ellipticity per residue in units of $\operatorname{deg} \times \mathrm{cm}^{2} \times \mathrm{dmol}^{-1}$. Analysis of the $\mathrm{CD}$ spectrum for the evaluation of secondary structure content was performed with DICHROWEB using the CONTIN algorithm [18].

\section{Indirect ELISA with antiserum anti-peptide}

The IEBD server (www.iedb.org) was used to predict the antigenic propensity of the URG7 protein [19]. The synthesized peptide conjugated to the carrier protein ovalbumin via an $\mathrm{N}$-terminal cysteine residue [20] was mixed in a 1:1 ratio with alum and finally used to immunize two male New Zealand white rabbits according to the standard procedure to obtaining a polyclonal antibody (PRIMM $\mathrm{srl}$, Milan). 96-well microtiterplates (NUNC Polysorp) incubated with 5\% glutaraldehyde for $1 \mathrm{~h}$ at room temperature (RT) were coated with synthetic peptide ( $1 \mu \mathrm{g} /$ well) in PBS (phosphate buffered saline) pH 7.6 or with recombinant His-URG7 polypeptide [14] (200 ng/well) in 70\% TFE overnight at $4{ }^{\circ} \mathrm{C}$. Controls were obtained by performing the assay in wells containing PBS without peptide and in wells coated with the recombinant His-URG7 polypeptide that recognized a commercially available monoclonal anti-polyHistidine-Peroxidase (Sigma). After washing with PBS-Tween $0.05 \%$, the wells were incubated with $5 \%$ (w/v) non-fat milk (NFM) in PBS for $2 \mathrm{~h}$ at $37^{\circ} \mathrm{C}$. After washing, rabbit purified antibodies were serially diluted in 1\% NFM in PBS and dispensed into the wells. The plates were incubated for $1 \mathrm{~h}$ at RT and then washed. Anti-rabbit-HRP conjugate (Santa Cruz Biotechnology, USA) diluted $1: 5000$ in $1 \%$ NFM in PBS was added and after incubation for $1 \mathrm{~h}$ at RT the plates were washed as above. The chromogen development was mediated by the addition of freshly prepared substrate solution (o-phenylenediamine dihydrochloride, Sigma). The reaction was stopped by the addition of $1 \mathrm{~N}$ sulfuric acid and the OD was measured at $450 \mathrm{~nm}$ on a microplate reader.

\section{Western blot analysis}

Recombinant His-URG7 polypeptide was resolved on a $15 \%$ polyacrylamide SDS gel and electroblotted onto nitrocellulose membranes. Membranes were blocked with $1 \%$ NFM at RT for $1 \mathrm{~h}$ and incubated with rabbit antibodies against the 75-99 peptide at RT for 1 h. Subsequently, HRP-conjugated secondary antibody (1:1000) was added and the membranes were incubated for $1 \mathrm{~h}$ at RT and, finally, developed using enhanced chemiluminescence reagents (ECL, Promega).

\section{Indirect ELISA with human sera}

To evaluate the presence of anti-URG7 antibodies in human sera, blood samples were obtained, after informed consent, from 12 healthy subjects ( 8 females of mean age $39 \pm 9$ and 4 males of mean age $43 \pm 4$ ) with no serologic evidence of HBV infection or biochemical evidence of liver disease and $30 \mathrm{HBV}$ infected patients ( 3 females of mean age 72 \pm 16 and 27 males of mean age $51 \pm 11$ ) positives both for HBsAg and HBV DNA and with alanine aminotransferase (ALT) $>40$ U/L. 96-well microtiterplates were coated with antigens as described above. After overnight incubation with human sera diluted 1:50 in 1\% NFM in PBS, anti-human IgG-HRP conjugate (Santa Cruz Biotechnology, USA) as a secondary antibody was used. All tests were performed in triplicate and appropriate negative controls were also made (evaluation of the absorbance in the wells incubated with only the patient's serum and secondary antibodies but without antigen). Each serum sample was tested blindly.

\section{Statistical analysis}

For statistical evaluations of significant differences, data were analyzed by using STATA for Windows Software;, Release 12, Stata Corp, (http://www.stata.com/) Box-plots display variations among populations and where outliers are located. The main statistics, as means and standard deviations, summarize the characteristics of the data. Response means between markers were compared by using a Tpaired test for the random sample from healthy subjects and a Kolmogorov-Smirnov test for the random sample from sick subjects. The Shapiro-Wilk test was used to check if the response data have a Gaussian distribution.

\section{Results and Discussion}

The increase of anti-URG7 antibodies in patients infected by the hepatitis $\mathrm{B}$ virus is related to a neoplastic transformation in hepatocellular carcinoma (HCC) [15,16]. For this purpose it is essential to have a sensitive and specific method for the determination of these antibodies. The simplest method for the determination of antibodies in serum is the ELISA test. Although it has been shown [16] that there is a statistically significant relationship between the presence of anti-URG7 antibodies against antigens $12-25$ and 56-70 of the URG7 protein and the onset of dysplastic nodules, it cannot be excluded that these antibodies were produced by the corresponding polypeptide sequences from the MRP6 protein. In order to obtain a specific URG7 antigen, the 75-99 peptide was synthesized and purified by reverse-phase liquid chromatography. Using the B-cell epitope prediction tool from the IEDB analysis resource (http:// tools.immuneepitope.org/tools/bcell/iedb_input) the antigenic propensity of the URG7 protein was determined. Different methods [21-26] which are based on parameters such as hydrophilicity, flexibility, accessibility, 
turns, exposed surface and polarity of the polypeptide chain help to identify a linear epitope in the aa 75-99 region (Figure 1).

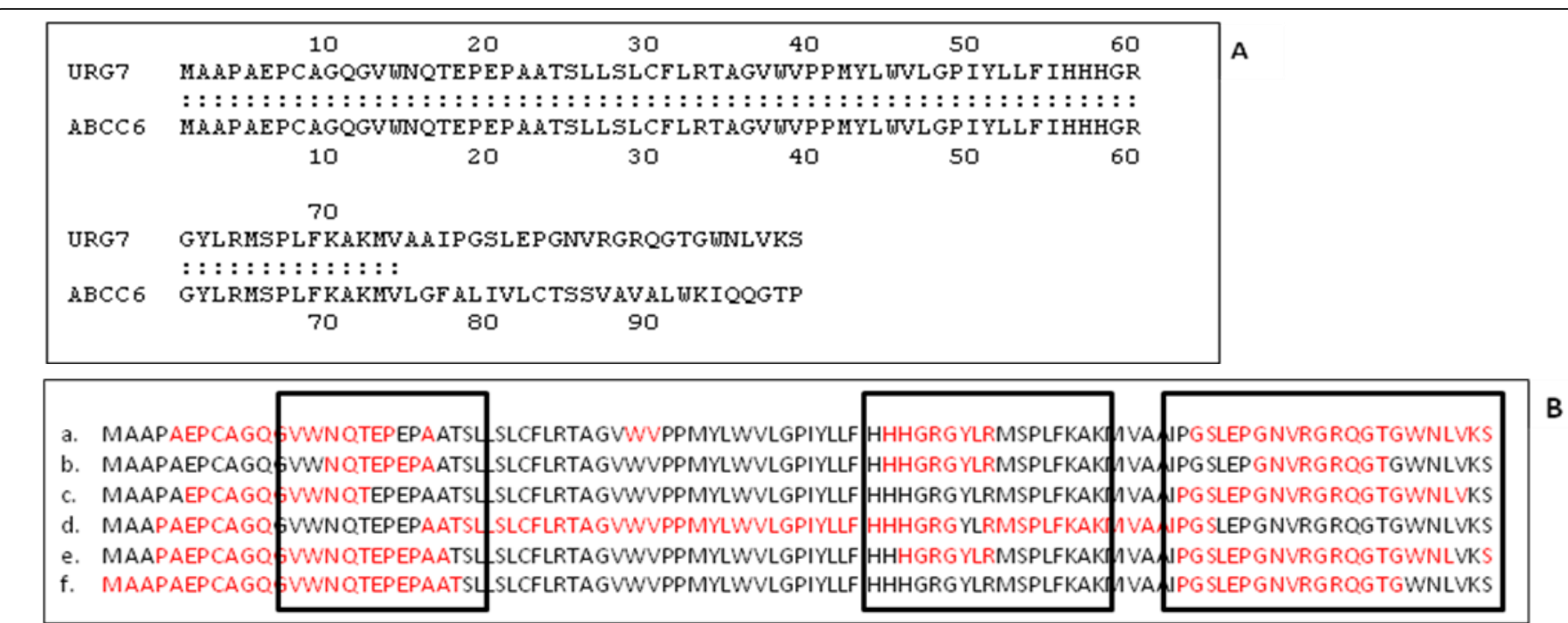

Figure 1: Prediction analysis of the antigenic propensity of the URG7 protein. A: Alignment of the URG7 sequence with the first 99aa residues of the ABCC6 protein. B: Potential linear peptides predicted to be antigenic determinants. Linear B-cell epitope prediction using the prediction tools of IEDB corresponding to the amino acid residues 12-25, 56-70 and 75-99 (residues in the boxes). The red letters show those sequences which can act as B-cell epitopes to elicit humoral immune response according to (a) [21] (b) [22] (c) [23] (d) [24] (e) [25] (f) [26]. The average antigenic index for epitopes by Chou \& Fasman method was 0.991, by Emini method was 1, by Karplus and Schulz method was 0.984, by Kolaskar and Tongaonkar method was 1.044, by Parker method was 0.490 and by Pontoppidan method was -0.009 .

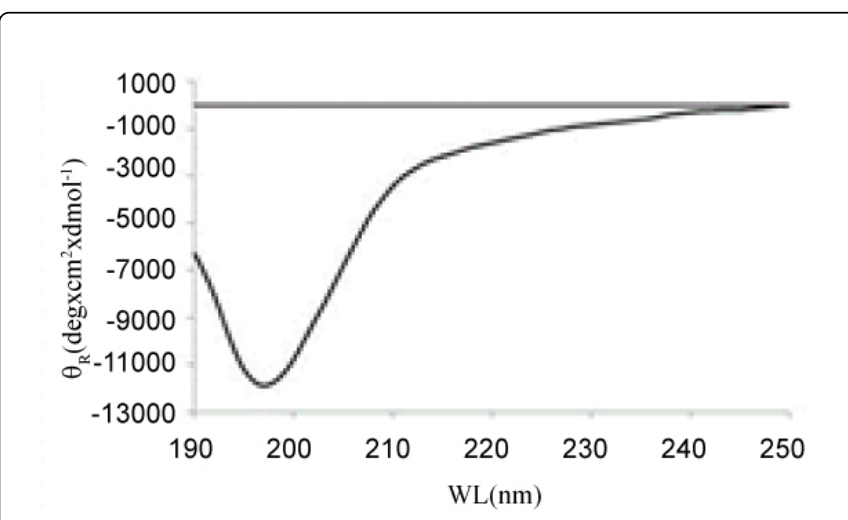

Figure 2: CD spectra of the 75-99 URG7 peptide. A peptide solution $50 \mu \mathrm{M}$ in $10 \mathrm{mM}$ phosphate buffer $\mathrm{pH} 6$ was analyzed. Data were expressed in terms of $[\theta] \mathrm{R}$, the molar ellipticity per residue.

The propensity of the short synthetic peptides to adopt secondary structure in solution was assessed by measurement of the circular dichroism (CD) ellipticity values [27]. The CD spectrum represented in Figure 2 was analyzed using the DichroWeb program. According to the results of the analysis, the $75-99$ peptides contains $31 \%$ of $\beta$-sheets strand, $24 \%$ of $\beta$-turns and $36 \%$ of unordered conformations. The percentage of $\alpha$-helix is rather low (9\%). All these data confirmed a high flexibility of peptide (due to its content in $\beta$-structures) and consequently a high antigenicity.

For effective immunization procedures and the generation of antipeptide antibodies, the use of peptide-protein conjugates is recommended [20]. Antisera, which were collected at the end of a standard course of immunization of rabbits against peptide conjugated to KLH (Keyhole Limpet Hemocyanin), were tested for ELISA characterization with peptide-ovalbumin conjugate, free peptide and His-URG7 polypeptide (Figure 3). No reactivity using pre-immune sera was detected, while with immune sera a strong immune response against 75-99 peptide-ovalbumin conjugate (Figure 3A), free 75-99 peptide and His-URG7 polypeptide (Figure $3 \mathrm{~B}$ ) was observed. The immunized rabbits developed antibodies capable of recognizing both the 75-99 peptide chain and the entire URG7 protein obtained by recombinant DNA technology.

The lower immunoreactivity of the antisera against the 75-99 peptides compared to that against the recombinant His-URG7 polypeptide at different antigen concentrations (Figure 3C) might be attributed to substantially different conformation(s) of the epitope sequence. The immune reactivity of the epitope sequence was confirmed by western blot analysis as well (Figure 4). The recombinant His-URG7 polypeptide was resolved by SDS-PAGE and blotted with rabbit antisera, as described in the Materials and Methods section. Immunoreactivity in denaturant conditions was observed at $100 \mathrm{ng}$ of polypeptide and a sera dilution of 1:3000. The band at molecular weight greater than $17 \mathrm{kDa}$ could correspond to an oligomeric form of the polypeptide. 


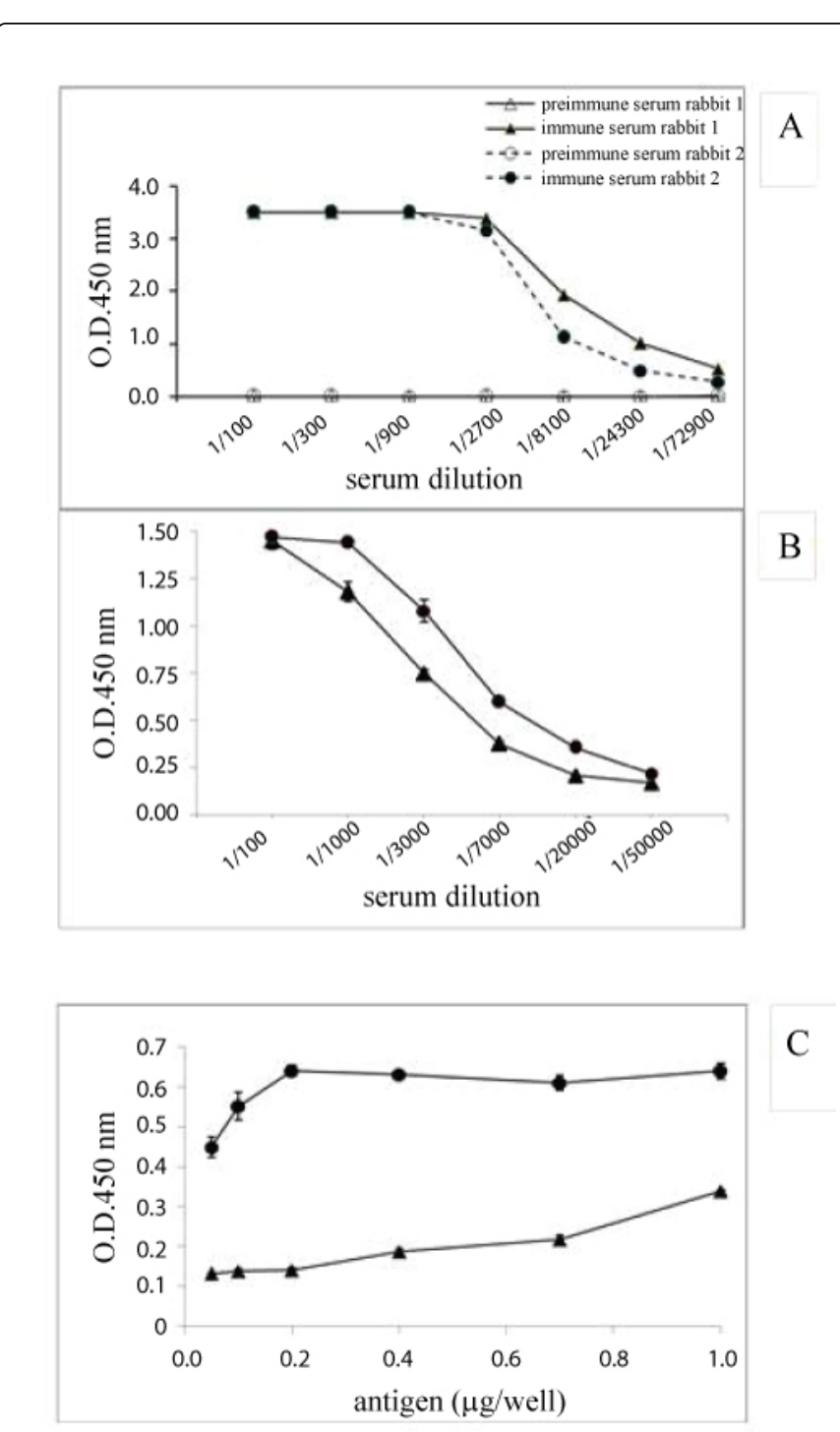

Figure 3: ELISA assay with rabbit polyclonal antibodies. Pre immune and immune serum of rabbit 1 and 2 were used for the detection of immobilized (A) 75-99 peptide conjugated with KLH ; (B) $1 \mu \mathrm{g} /$ well $75-99$ peptide alone $(\boldsymbol{\Delta})$ and $0.2 \mu \mathrm{g} /$ well recombinant His-URG7 polypeptide $(\bullet)$; (C) reactivity of rabbit polyclonal serum (1:7000 dilution) to different immobilized amounts of 75-99 peptide $(\boldsymbol{\Lambda})$ and recombinant His-URG7 polypeptide $(\bullet)$.

In order to verify the specificity of the antigen 75-99 peptide to recognize human anti-URG7 antibodies, ELISA was performed immobilizing separately the 75-99 peptide (Figure 5A) and the recombinant His-URG7 polypeptide (Figure $5 \mathrm{~B}$ ) and using human sera of both healthy subjects and HBV infected patients (sick). For both antigens, box-plots in Figure 5 show a greater variability in the upper distribution when the random sample from sick subjects is compared with the random sample from healthy subjects. Random sample related to the healthy subjects has a Gaussian distribution ( $p$-value 0.50 for 75-99 peptide and p-value 0.24 for His-URG7 polypeptide), whereas random sample related to the sick subjects does not ( $\mathrm{p}$-value $<0.05$ ).
Comparison of the responses between 75-99 peptide and His-URG7 polypeptide from the sick subjects shows different theoretical models underlying the population (Kolmogorov-Smirnov test, p-value 0.03). This is not true for the healthy subjects (Kolmogorov-Smirnov test, $\mathrm{p}$ value 0.09). The response means to the antigens are different either for healthy subjects ( $\mathrm{p}$-value 0.0003 ) and either for sick subjects ( $\mathrm{p}$-value $0.03)$.

As suggested by the literature and according to the Gaussian hypothesis on a healthy population, we fixed the threshold value at the 68-th percentile of the sample. This threshold is equal to 0.087 for 75-99 peptide and for His-URG7 polypeptide this threshold is below and/or equal to 0.036 . These two values are statistically different (Kolmogorov-Smirnov test, p-value of 0.03). Therefore, the discriminant threshold, to check the significance response to the ELISA test, is higher for 75-99 peptide.

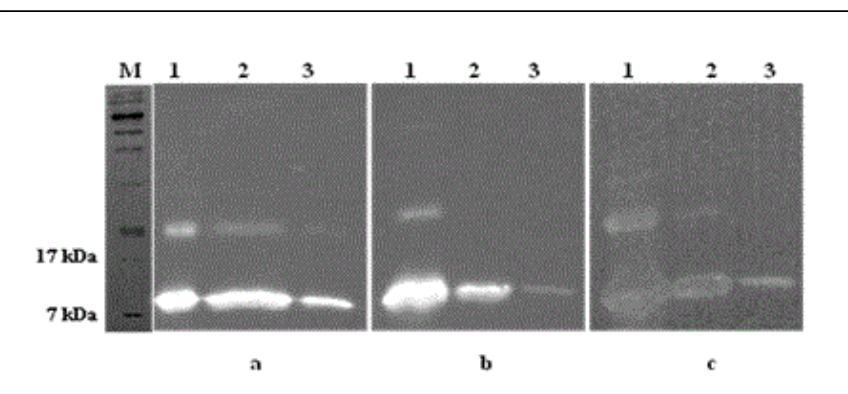

Figure 4: Western blot analysis of recombinant His-URG7 polypeptide. His-URG7 (lane 1, 1 $1 \mu \mathrm{g}$; lane 2, $0.1 \mu \mathrm{g}$; lane 3, $0.01 \mu \mathrm{g}$ ) was resolved by SDS-PAGE. Protein was transferred to nitrocellulose membranes and blotted with 1:1000 (a), 1:3000 (b) and 1:7000 (c) rabbit antisera elicited against the 75-99 peptides. Positions of the molecular weight standards $(\mathrm{kDa})$ are indicated in the left lane.

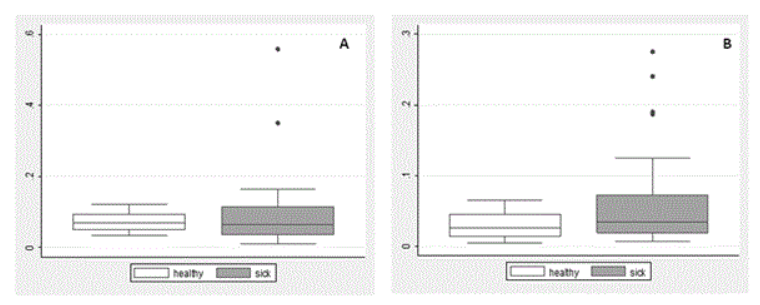

Figure 5: Box plot of data sampled from healthy and sick populations. Statistical analysis are shown for 75-99 peptide in Figure $5 \mathrm{~A}$ and for recombinant His-URG7 polypeptide in Figure 5B. SD 0.11 for $75-99$ peptides and SD 0.75 for His-URG7 polypeptide in sick subjects, while SD 0.027 for 75-99 peptide and SD 0.021 for His-URG7 polypeptide in healthy subjects. The points outside the box plot are outliers.

Altogether, the antigen spanning aa75-99 allows for the detection with good sensitivity and specificity of anti-URG7 antibodies in sera of HBV infected patients. 


\section{Conclusion}

Immuno-informatics tools and secondary structure analysis of the synthetic peptide corresponding to the unique sequence aa75-99 belonging to the URG7 protein allowed identifying the antigenic properties of that peptide. Sera from immunized rabbits exhibited a strong immune response against the sequence 75-99 in an indirect ELISA test. Finally preliminary ELISA assay against this specific sequence of the URG7 protein allowed with good sensitivity and specificity for the detection of anti-URG7 antibodies in sera from HBV infected patients.

\section{Conflict of Interest}

To the best of our knowledge, no conflict of interest exists.

\section{References}

1. Ringelhan M, O'Connor T, Protzer U, Heikenwalder M (2015) The direct and indirect roles of HBV in liver cancer: prospective markers for HCC screening and potential therapeutic targets. J Pathol 235: 355-367.

2. Kew MC (2011) Hepatitis B virus $x$ protein in the pathogenesis of hepatitis B virus-induced hepatocellular carcinoma. J Gastroenterol Hepatol 26: 144-152.

3. Hung CM, Huang WC, Pan HL, Chien PH, Lin CW, et al. (2014) Hepatitis $\mathrm{B}$ virus $\mathrm{X}$ up regulates $\mathrm{HuR}$ protein level to stabilize HER2 expression in hepatocellular carcinoma cells. Biomed Res Int 2014: 827415 .

4. Liu H, Ye L, Wang QW, Yan QX, Yu JM (2009) Effect of a conserved peptide derived from Kunitz domain of hepatitis B virus $\mathrm{x}$ protein on the cell cycle and apoptosis of HepG2 cells via the proteasome pathway. Chin Med J 122: 460-465

5. Tan YL, Chen WN (2014) MicroRNAs as therapeutic strategy for hepatitis B virus associated hepatocellular carcinoma: Current status and future prospects WJG 20th Anniversary Special Issues (1): Hepatocellular carcinoma. World J Gastroenterol 20: 5973-5986.

6. Chen X, Cheung ST, So S, Fan ST, Barry C, et al. (2002) Gene expression patterns in human liver cancers. Mol Biol Cell 13: 1929-1939.

7. Lian Z, Liu J, Pan J, Satiroglu Tufan NL, Zhu M, et al. (2001) A cellular gene up-regulated by hepatitis $\mathrm{B}$ virus-encoded $\mathrm{X}$ antigen promotes hepatocellular growth and survival. Hepatol 34: 146-157.

8. Piehler AP, Hellum M, Wenzel JJ, Kaminski E, Haug KB, et al. (2008) The human $\mathrm{ABC}$ transporter pseudogene family: Evidence for transcription and gene-pseudogene interference. BMC Genomics 9: 165.

9. Vanakker OM, Hosen MJ, Paepe AD (2013) The ABCC6 transporter: what lessons can be learnt from other ATP-binding cassette transporters? Front Genet 4: 203.

10. Pan J, Lian Z, Wallet, Feitelson MA (2007) The hepatitis B $x$ antigen effector, URG7, blocks tumor necrosis factor mediated apoptosis by activation of phosphoinositol 3-kinase e beta catenin. J Gen Viral 88: 3275-3282.
11. Feitelson MA, Reis HM, Tufan NL, Sun B, Pan J, et al. (2009) Putative roles of hepatitis $\mathrm{B} x$ antigen in the pathogenesis of chronic liver disease. Cancer Lett 286: 69-79.

12. Ostuni A, Lara P, Armentano MF, Miglionico R, Salvia AM, et al. (2013) The hepatitis B x antigen anti-apoptotic effector URG7 is localized to the endoplasmic reticulum membrane. FEBS Lett 587: 3058-3062.

13. Sonnhammer EL, von Heijne G, Krogh A (1998) A hidden Markov model for predicting transmembrane helices in protein sequences. Proc Int Conf Intell Syst Mol Biol 6: 175-182.

14. Ostuni A, Castiglione Morelli MA, Miglionico R, Salvia AM, Cuviello F, et al. (2014) Expression, purification and structural characterization of up-regulated gene 7 encoded protein. Protein Pept Lett 21: 413-418.

15. Hann HW, Lee J, Bussard A, Liu C, Jin YR, et al. (2004) Preneoplastic markers of Hepatitis B virus-associated hepatocellular carcinoma. Cancer Res 64: 7329-7335.

16. Wang W, Zhao LJ, Wang Y, Tao QY, Feitelson MA, et al. (2012) Application of $\mathrm{HBx}$-induced anti-URGs as early warning biomarker of cirrhosis and HCC. Cancer Biomarkers 11: 29-39.

17. Ostuni A, Miglionico R, Bisaccia F, Castiglione Morelli MA (2010) Biochemical characterization and NMR study of the region E748-A785 of the human protein MRP6/ABCC6. Protein Pept Lett 17: 861-866.

18. Whitmore L, Wallace BA (2004) DICHROWEB: an online server for protein secondary structure analyses from circular dichroism spectroscopic data. Nucleic Acids Res 32: W668-W673.

19. Vita R, Zarebski L, Greenbaum JA, Emami H, Hoof I, et al. (2010) The immune epitope database 2.0. Nucleic Acids Res 38: D854-D862.

20. Trier NH, Hansen PR, Houen G (2012) Production and characterization of peptide antibodies. Methods 56: 136-144.

21. Chou PY, Fasman GD (1978) Prediction of the secondary structure of the proteins from their amino acid sequences. Adv Enzymol Relat Areas Mol Biol 47: 45-148.

22. Emini EA, Hughes JV, Perlow DS, Boger J (1985) Induction of hepatitis A virus-neutralizing antibody by a virus-specific synthetic peptide. J Virol 55: 836-839.

23. Karplus PA, Schulz GE (1985) Prediction of Chain Flexibility in Proteins A tool for the Selection of Peptide Antigens. Naturwissenschafren 72: 212-213.

24. Kolaskar AS, Tongaonkar PC (1990) A semi-empirical method for prediction of antigenic determinants on protein antigens. FEBS Lett 276: 172-174.

25. Parker JM, Guo D, Hodges RS (1986) New hydrophilicity scale derived from high-performance liquid chromatography peptide retention data: correlation of predicted surface residues with antigenicity and X-rayderived accessible sites. Biochemistry 25: 5425-5432.

26. Pontoppidan Larsen JE, Lund O, Nielsen M (2006) Improved method for predicting linear B-cell epitopes. Immunome Res 2: 2 .

27. Greenfield NJ (2006) Using circular dichroism spectra to estimate protein secondary structure. Nat Protoc 1: 2876-2890. 